\title{
Article \\ Utilization of Marine Waste to Obtain $\beta$-Chitin Nanofibers and Films from Giant Humboldt Squid Dosidicus gigas
}

\author{
Gustavo Cabrera-Barjas ${ }^{1, *(\mathbb{D}, \text { Cristian González }}{ }^{2}$, Aleksandra Nesic ${ }^{1,3, *}$, Kelly P. Marrugo $^{4}$, Oscar Gómez ${ }^{5}$, \\ Cédric Delattre ${ }^{6,7}\left(\mathbb{D}\right.$, Oscar Valdes $^{8}{ }^{\circledR}$, Heng Yin ${ }^{9}$, Gaston Bravo ${ }^{1}$ and Juan Cea ${ }^{1}$
}

1 Unidad de Desarrollo Tecnológico, Parque Industrial Coronel, Universidad de Concepción, Concepción 3349001, Chile; g.bravo@udt.cl (G.B.); j.cea@udt.cl (J.C.)

2 Facultad de Ingeniería, Universidad del Bío-Bío, Concepción 4051381, Chile; crlgonza@alumnos.ubiobio.cl

3 Department of Chemical Dynamics and Permanent Education, Vinca Institute of Nuclear Sciences-National Institute of the Republic of Serbia, University of Belgrade, Mike Petrovica-Alasa 12-14, 11000 Belgrade, Serbia

4 Departamento de Físico-Química, Facultad de Ciencias Químicas, Universidad de Concepción, Edmundo Larenas 129, Casilla 160-C, Concepción 4070371, Chile; kmarrugo@udec.cl

5 Carbon and Catalysis Laboratory (CarboCat), Department of Chemical Engineering, University of Concepción, Concepción 4030000, Chile; ogomez@udec.cl

6 Clermont Auvergne INP, Université Clermont Auvergne, CNRS, Institut Pascal, F-63000 Clermont-Ferrand, France; cedric.delattre@uca.fr

7 Institute Universitaire de France (IUF), 1 rue Descartes, 75005 Paris, France

8 Centro de Investigación de Estudios Avanzados del Maule (CIEAM), Vicerrectoría de Investigación y Postgrado, Universidad Católica del Maule, Talca 3460000, Chile; ovaldes@ucm.cl

9 Dalian Engineering Research Center for Carbohydrate Agricultural Preparations, Liaoning Provincial Key Laboratory of Carbohydrates, Dalian Institute of Chemical Physics, Chinese Academy of Sciences, Dalian 116023, China; yinheng@dicp.ac.cn

Citation: Cabrera-Barjas, G.; González, C.; Nesic, A.; Marrugo, K.P.; Gómez, O.; Delattre, C.; Valdes, O.; Yin, H.; Bravo, G.; Cea, J. Utilization of Marine Waste to Obtain $\beta$-Chitin Nanofibers and Films from Giant Humboldt Squid Dosidicus gigas. Mar. Drugs 2021, 19, 184. https://doi.org/10.3390/md19040184

Academic Editor: Hitoshi Sashiwa

Received: 10 February 2021

Accepted: 24 March 2021

Published: 26 March 2021

Publisher's Note: MDPI stays neutral with regard to jurisdictional claims in published maps and institutional affiliations.

Copyright: (c) 2021 by the authors. Licensee MDPI, Basel, Switzerland. This article is an open access article distributed under the terms and conditions of the Creative Commons Attribution (CC BY) license (https:// creativecommons.org/licenses/by/ $4.0 /)$.

Abstract: $\beta$-chitin was isolated from marine waste, giant Humboldt squid Dosidicus gigas, and further converted to nanofibers by use of a collider machine under acidic conditions ( $\mathrm{pH} 3$ ). The FTIR, TGA, and NMR analysis confirmed the efficient extraction of $\beta$-chitin. The SEM, TEM, and XRD characterization results verified that $\beta$-chitin crystalline structure were maintained after mechanical treatment. The mean particle size of $\beta$-chitin nanofibers was in the range between 10 and $15 \mathrm{~nm}$, according to the TEM analysis. In addition, the $\beta$-chitin nanofibers were converted into films by the simple solvent-casting and drying process at $60{ }^{\circ} \mathrm{C}$. The obtained films had high lightness, which was evidenced by the CIELAB color test. Moreover, the films showed the medium swelling degree (250-290\%) in aqueous solutions of different $\mathrm{pH}$ and good mechanical resistance in the range between 4 and $17 \mathrm{MPa}$, depending on film thickness. The results obtained in this work show that marine waste can be efficiently converted to biomaterial by use of mild extractive conditions and simple mechanical treatment, offering great potential for the future development of sustainable multifunctional materials for various industrial applications such as food packaging, agriculture, and/or wound dressing.

Keywords: Humboldt giant squid; $\beta$-chitin; nanofibers; characterization; films

\section{Introduction}

In Chile, near 46,000 ton/month of Humboldt squids (Dosidicus gigas Wild) are caught for human consumption. According to the annual fishing statistics reports from 2019, the Chilean fishing quota of the giant squid of Humboldt is 200,000. During its industrial processing, the squid pen is generated as a by-product, which is currently used as a fish flour extender, which presents low value-added processing. Hence, there is an urgent need for the development of new strategies to convert marine waste into value-added materials from an economical point of view. One of the approaches is the extraction of components from waste and by-products of the fishery industry and their conversion to value-added 
materials [1-3]. Particular attention is given to squid pens because they are a valuable source of $\beta$-chitin and protein.

Generally, chitin or poly $(\beta-(1 \rightarrow 4)-N$-acetyl-D-glucosamine) is a natural polysaccharide derived from large numbers of living organisms [4-6]. It is the second most abundant natural polymer, next to cellulose. In the native state, chitin occurs as ordered crystalline microfibrils, which are structural components in the exoskeleton of arthropods or fungal cell walls. Depending on its source, chitin exists as two crystalline allomorphs, namely in $\alpha$ - and $\beta$-form. The $\alpha$-chitin isomorph is by far the most abundant because it can be found in the exoskeletons of crustaceans and cell walls of fungi and yeasts. On the other hand, $\beta$-chitin is rare in nature and is found in association with proteins in squid pens and the tubes of some worms $[7,8]$. The $\alpha$-chitin was mainly studied due to vast abundance; however, this allomorph is highly crystalline and insoluble in aqueous or common organic solvents, limiting its application. In addition, when it comes to the extraction process of $\alpha$-chitin from crustaceans, the general procedure requires a first demineralization process using a dilute mineral acid for several hours to separate calcium carbonate. Then, a deproteinization under harsh conditions (high temperature and longtime of treatment) is required to extract proteins. The amount of extracted chitin at these conditions is approximately $20 \%$. On the other hand, the extraction of $\beta$-chitin from squid pens does not require harsh demineralization conditions since squid pens contain only up to $5 \%$ of minerals. The yield of $\beta$-chitin extracted from squid pen is usually around $50 \%$ [9]. It is known that $\beta$-chitin is less crystalline allomorph and more soluble in organic solvents, making this type of chitin more reactive. Moreover, due to parallel chain arrangements, the $\beta$-chitin-based material possesses higher mechanical stability than $\alpha$-chitin based material [10]. Hence, squid pen presents a beneficial source of chitin from the environmental and economical point of views, where the extraction process can be performed at mild conditions, with reduced chemical and energy consumption, and higher reactivity of obtained biopolymer, in comparison to the $\alpha$-chitin obtained from crustaceans.

The present work aims to obtain and characterize $\beta$-chitin microfibers (MF) and nanofibers (NF) from squid pen Dosidicus gigas. Up to date, there are several studies in the literature for the extraction of $\beta$-chitin from different species of squid pens [11-13]. However, the conversion of $\beta$-chitin microfibrils into $\beta$-chitin nanofibrils and their detailed characterization is a new topic, and only a few papers in the literature can be found. Suenaga et al. studied the Star Burst system (wet pulverization technique under high pressure) to obtain $\beta$-chitin nanofibers in distilled water and under acidic conditions $[7,14]$. Ifuku et al. also used the Star Burst system to obtain chitin nanofibers [15]. On the other hand, numerous methods were used to obtain $\alpha$-chitin nanofibers such as ultrasonication [16], grinding [17], or dynamic high-pressure homogenization under acidic conditions [18]. This work will present a new and simple method to process $\beta$-chitin nanofibers at a bench-scale of low energy and acid consumption. Namely, $\beta$-chitin microfibers were dispersed in an acidic aqueous solution ( $\mathrm{pH} 3$ ) and converted into nanofibers by pass-through a collision machine. SEM, TEM, and XRD characterized the obtained nanofibers. It is important to underline that obtained $\beta$-chitin nanofibers can be directly shaped into transparent films by a simple drying method in the oven. Hence, chitin nanofibers-based films were also characterized along with the raw material and nanofibers by different physicochemical and microscopic techniques. These chitin nanofibers can find applications in food, cosmetics, biomaterials, agriculture, electronics, adhesive, and biomaterials areas [19-24].

\section{Results and Discussion}

\subsection{Squid Pen and $\beta$-Chitin Isolated Composition}

It is well known that the chemical composition of squid pens depends on species; therefore, ash content can vary from $0.02-2.4 \%$, protein content from $43-76 \%$, and chitin content from $25-50 \%$ [19]. The chemical composition of squid pen and isolated $\beta$-chitin is presented in Table 1. It has been proven that squid D. gigas pen is an excellent source of chitin ( $30.2 \%$ by dry weight). Similar chitin content of squid pens was obtained in 
the literature for various species: Todarodes pacifica (26\%) [19], Illex argentinus (31\%) [9], Loligo vulgaris (31\%) [25], and Sepioteuthis lessoniana (40\%) [26].

Table 1. Chemical characterization of $D$. gigas squid pen and $\beta$-chitin.

\begin{tabular}{cccccccc}
\hline Sample & $\begin{array}{c}\text { Humidity } \\
(\mathbf{\%})\end{array}$ & Ashes (\%) & Lipid (\%) & Chitin (\%) & Protein (\%) & DA (\%) & Ref \\
\hline Squid pen & $23.3 \pm 1.2$ & $1.8 \pm 0.2$ & $0.4 \pm 0.1$ & $30.2 \pm 0.5$ & $67.5 \pm 0.4$ & - & Present work \\
Loligo vulgaris & - & $1.7 \pm 0.1$ & $0.32 \pm 0.04$ & $40.0 \pm 1.5$ & $36.5 \pm 0.6$ & - & {$[27]$} \\
Loligo chenisis & - & $1.4 \pm 0.2$ & $1.9 \pm 0.2$ & $35.8 \pm 1.8$ & $57.2 \pm 2.3$ & - & {$[12]$} \\
Todarodes pacifica & - & $0.8 \pm 0.1$ & $0.20 \pm 0.01$ & $25.5 \pm 0.4$ & $74.6 \pm 0.3$ & - & {$[26]$} \\
Illex argentinus & - & $0.1 \pm 0.1$ & $2.3 \pm 0.2$ & $31.0 \pm 0.6$ & $64.0 \pm 0.7$ & - & {$[11]$} \\
$\quad \beta$-Chitin & $10.1 \pm 0.9$ & $0.7 \pm 0.2$ & - & - & $0.7 \pm 0.1$ & 96.4 & Present work \\
\hline
\end{tabular}

The average ash, lipid, and protein contents of the squid pen D. gigas were $1.8 \%, 0.40 \%$, and $67.5 \%$, respectively. The ash content of squid pen D. gigas is similar to the one for squid pen Loligo sp. (1.9\%) [13] and Loligo vulgaris (1.7\%) [27]. The squid pen D. gigas has been shown to be a good source of protein $(68 \%)$, and this is also observed for the squid pen Loligo Chenisis (57\%) [12], Illex argentinus (64\%) [11], and Todarodes pacifica (75\%) [19].

The extraction of $\beta$-chitin from squid pen was performed by demineralization in $\mathrm{HCl}(1 \mathrm{M})$ and deproteinization in $\mathrm{NaOH}(1 \mathrm{M})$. The yield of extracted chitin was $39.4 \%$. Other authors reported similar yields for the extraction of $\beta$-chitin from squid pens $(35-42 \%)[12,13]$. It can be noticed that inorganic compounds are significantly removed $(<1 \%)$ during extraction of $\beta$-chitin, which is evidenced by reduced ash content. Regarding the DA of obtained $\beta$-chitin, it was higher than reported from Loligo Chenisis squid pen (80.3\%) [12], but lower than reported for Loligo vulgaris (100\%) [27].

Molecular weight determination of chitin samples is quite complex because it requires sophisticated analytical capabilities. Hence, simple indirect methods to compare the macromolecules' molecular weight are used. Among these, viscosity methods are very cheap and useful. The reduced viscosity parameter is measured in a dilute solution of macromolecules and can provide information on its shape, flexibility, and (for no spherical particles) molar mass of macromolecules. It can be used as a comparison value because of its concentration-dependent nature. The obtained $\eta_{\text {red }}$ value for the $\beta$-chitin sample was high $(2648 \mathrm{mg} / \mathrm{mL})$, suggesting that this macromolecule can have a high molecular weight, and the employed extraction method does not lead to an extensive chain degradation. This result agrees with previously reported values of reduced viscosity for other crustacean and squid pen $\beta$-chitin [28].

\subsection{Physicochemical Characterization of $\beta$-Chitin \\ 2.2.1. ${ }^{13} \mathrm{C} \mathrm{CP} /$ MAS Solid-State NMR Analysis}

The degree of deacetylation of isolated $\beta$-chitin was determined by ${ }^{13} \mathrm{C} C \mathrm{C} / \mathrm{MAS}$ solid-state equipment and spectrum is presented in Figure 1. Seven signals were detected that were ascribed to the eight carbon atoms of the $N$-acethylglucosamine repetitive unit, which appear at the following chemical shifts: $\delta=173.3 \mathrm{ppm}(\mathrm{C}=\mathrm{O}), 104.5 \mathrm{ppm}(\mathrm{C}-1)$, $85.2 \mathrm{ppm}(\mathrm{C}-4), 75.7 \mathrm{ppm}$ (C-3 and C-5), $59.9 \mathrm{ppm}(\mathrm{C}-6), 55.8 \mathrm{ppm}(\mathrm{C}-2)$, and $23.2 \mathrm{ppm}$ $\left(\mathrm{CH}_{3}\right)$. The $\mathrm{C}=\mathrm{O}$ signal appears as a sharp and symmetric profile. The $\mathrm{C}-3$ and $\mathrm{C}-5$ signals merge into a single resonance centered at $75.6 \mathrm{ppm}$, which is a characteristic pattern for $\beta$-chitin. All of these signals are typical for $\beta$-chitin and confirm its conformational state. The relative intensities of the resonance of the ring carbon (IC1, IC2, IC3, IC4, IC5, IC6) and $\mathrm{CH}_{3}$ group $\left(\mathrm{I}_{\mathrm{CH} 3}\right)$ were compared in order to calculate the degree of acetylation (DA) value. It was found that the DA of $\beta$-chitin isolated from D. gigas was $96.4 \%$. Generally, DA of chitin obtained from different species of squid pen varies from 80 to $98 \%$, depending on the different extraction parameters: presence or absence of demineralization process, time, and temperature of operated demineralization and deproteinization process as well as the 
concentration of solutions used for these processes $[11,24,25,29,30]$. The high content of DA obtained in this work indicates that mild extraction conditions for the extraction of chitin are used, thus preserving the native structure of $\beta$-chitin.

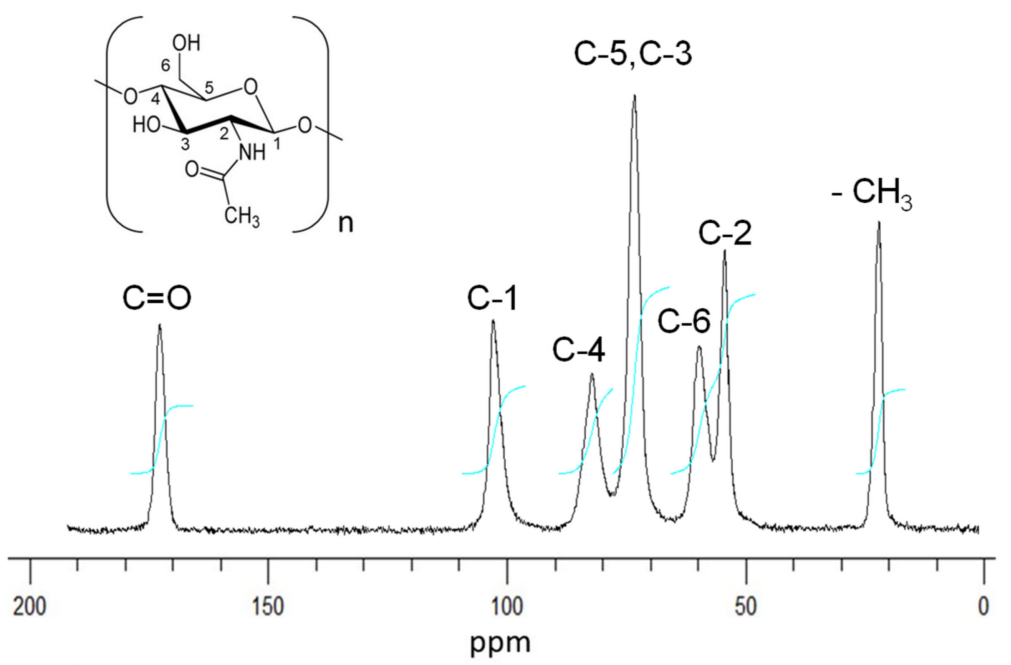

Figure $1 .{ }^{13} \mathrm{C} C P /$ MAS NMR spectra of $D$. gigas $\beta$-chitin.

\subsubsection{FTIR Analysis}

The FTIR spectra of squid pen and isolated $\beta$-chitin are presented in Figure 2 . The main difference between spectra (e.g., the bands intensity, band shifting, and some signals overlapping) is due to the raw material protein contents, as previously discussed (see Section 2.1). Hence, the main focus will be given to the discussion of the $\beta$-chitin spectra. The $\beta$-chitin FTIR spectra patterns are similar to those reported in the literature [7], suggesting that good chitin quality had been obtained. An exhaustive examination of the spectrum revealed that the spectra had the characteristic bands of polysaccharides. Namely, the wide area in the region between 3600 and $3000 \mathrm{~cm}^{-1}$ was detected: bands at 3472,3326 , and $3101 \mathrm{~cm}^{-1}$, which correspond to the stretching vibration of $-\mathrm{OH}$ and $-\mathrm{NH}$ groups $\left(v \mathrm{OH}, v^{\text {as }} \mathrm{NH}\right.$, and $\left.v^{s} \mathrm{NH}\right)$, respectively. The first band belongs to $-\mathrm{OH}$ groups involved in hydrogen bonds $(\mathrm{O}-6-\mathrm{H} \cdots \mathrm{O}=\mathrm{C}$ and $\mathrm{O}-3-\mathrm{H} \cdots \mathrm{O}-5)$. The other two bands are due to $\mathrm{C}=\mathrm{O}$ $\cdot \mathrm{H}-\mathrm{N}$ intermolecular hydrogen bonding and $\mathrm{H}$ bonded $-\mathrm{NH}$ groups, respectively. The chitin characteristic bands related to $-\mathrm{CH}$ groups stretching vibration appears at $2962 \mathrm{~cm}^{-1}$ $\left(v^{\text {as }} \mathrm{CH}_{3}\right), 2929 \mathrm{~cm}^{-1}\left(v_{\mathrm{CH} 2}^{\mathrm{s}}\right)$, and $2880 \mathrm{~cm}^{-1}\left(v^{\mathrm{as}} \mathrm{CH}_{3}\right)$. Moreover, the spectra also feature characteristic bands at 1627,1548, and $1313 \mathrm{~cm}^{-1}$ that are describing the vibrations of Amide I (primarily $\mathrm{C}=\mathrm{O}$ stretch), Amide II (bending vibration of $\mathrm{N}-\mathrm{H}$ ), and Amide III $\left(v_{\mathrm{C}-\mathrm{N}}+\delta_{\mathrm{NH}}\right)$ groups, respectively. The presence of one single peak in the region between 1600 and $1670 \mathrm{~cm}^{-1}$ confirms the presence of $\beta$-chitin. It is known that the carbonyl oxygen of the acetamide group formed intermolecular hydrogen bonding between the primary $-\mathrm{OH}$ and $-\mathrm{NH}_{2}$ groups, forming a two-dimensional hydrogen bonding network in a plane perpendicular to the pyranosyl plane. The spectra of $\beta$-chitin also revealed two additional bands of $-\mathrm{CH}$ group deformations around $1425\left(\delta_{\mathrm{CH} 2}\right)$ and $1375 \mathrm{~cm}^{-1}\left(\delta_{\mathrm{CH}}+\delta_{\mathrm{C}-\mathrm{CH} 3}\right)$, and a greater number of narrower bands in the region between 1200 and $1032 \mathrm{~cm}^{-1}$, related to $\mathrm{C}-\mathrm{O}-\mathrm{C}$ and $\mathrm{C}-\mathrm{O}$ stretching vibrations. Another characteristic marker is the $\mathrm{CH}$ deformation of the $\beta$-glycosidic bond. This band appears in $\beta$-chitin at $895 \mathrm{~cm}^{-1}(\gamma \mathrm{CH}$, $\mathrm{C} 1$ axial of $\beta$-linkage). Therefore, FTIR analysis confirmed that the isolated biopolymer is $\beta$-chitin. This result is in agreement with the results obtained by ${ }^{13} \mathrm{C} \mathrm{CP} / \mathrm{MAS}$ NMR analysis, where the crystalline structure of identified chitin was proven. 


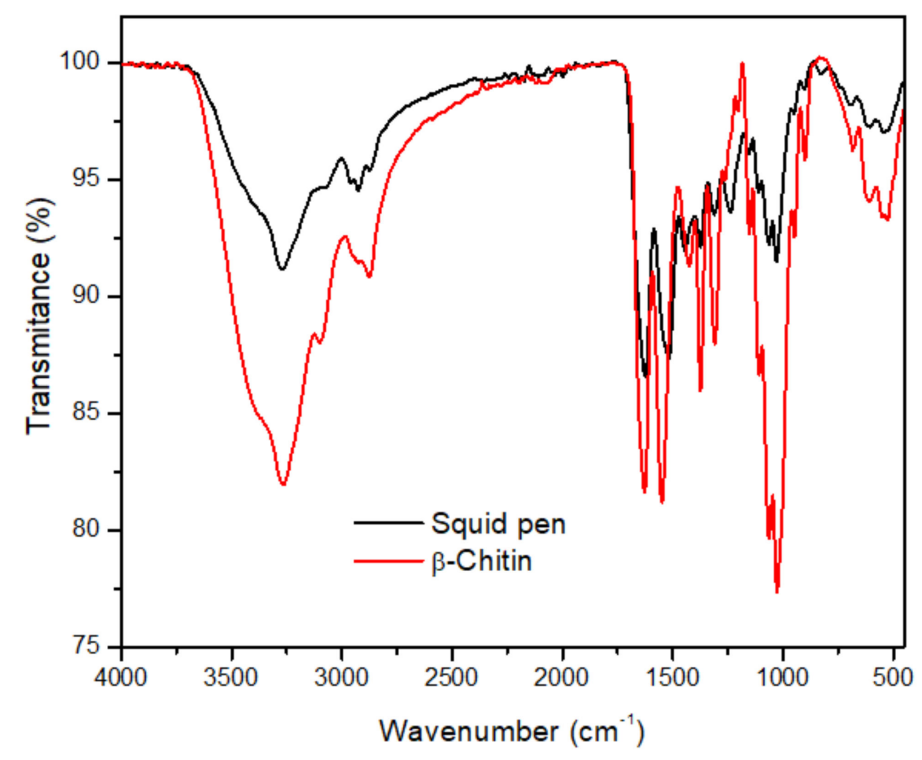

Figure 2. FTIR analysis of $D$. gigas squid pen and isolated $\beta$-chitin.

\subsubsection{Thermogravimetric Analysis}

Thermograms of squid pen and isolated $\beta$-chitin are shown in Figure 3. The thermal analyses of squid pen and isolated $\beta$-chitin were undertaken in the interval from 20 to $550{ }^{\circ} \mathrm{C}$. The thermogravimetric (TG) and its derivate (DTG) curves are presented in Figure 4 . The squid pen's overall decomposition process (66\% weight loss) consists of three degradation steps, which are reflected as three peaks in the DTG curve. The first degradation stage $\left(25-126^{\circ} \mathrm{C}\right)$, with the maximum degradation at $46^{\circ} \mathrm{C}$ is due to the water evaporation in the squid pen, and it accounted for a weight loss of $23 \%$. In the range of $126-264{ }^{\circ} \mathrm{C}$, the second weight loss can be attributed to the depolymerization and degradation of the squid pen proteins that wrap chitin fibers. This stage is the main difference between squid pen and isolated $\beta$-chitin thermograms. A third stage between 264 and $550{ }^{\circ} \mathrm{C}$ and maximum degradation at $294^{\circ} \mathrm{C}$ is caused by the degradation, pyrolysis, vaporization, and elimination of the volatile products of remaining proteins and the chitin chain [31].
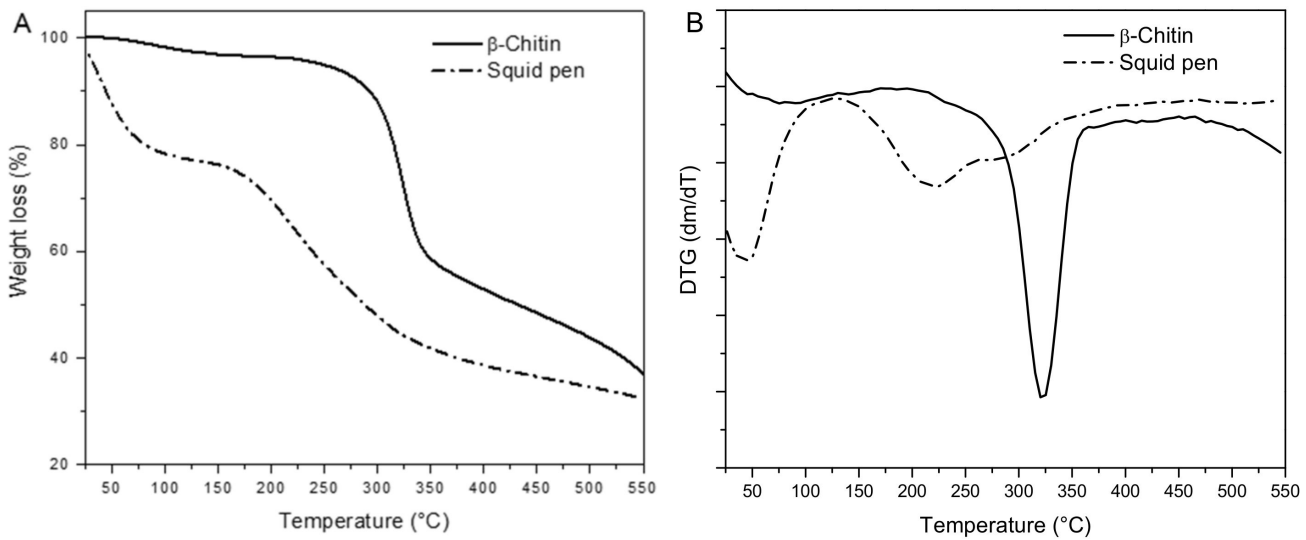

Figure 3. Thermogravimetric (TG) curves. (A) TG and (B) derivate thermogravimetric (DTG) of D. gigas squid pen and isolated $\beta$-chitin. 


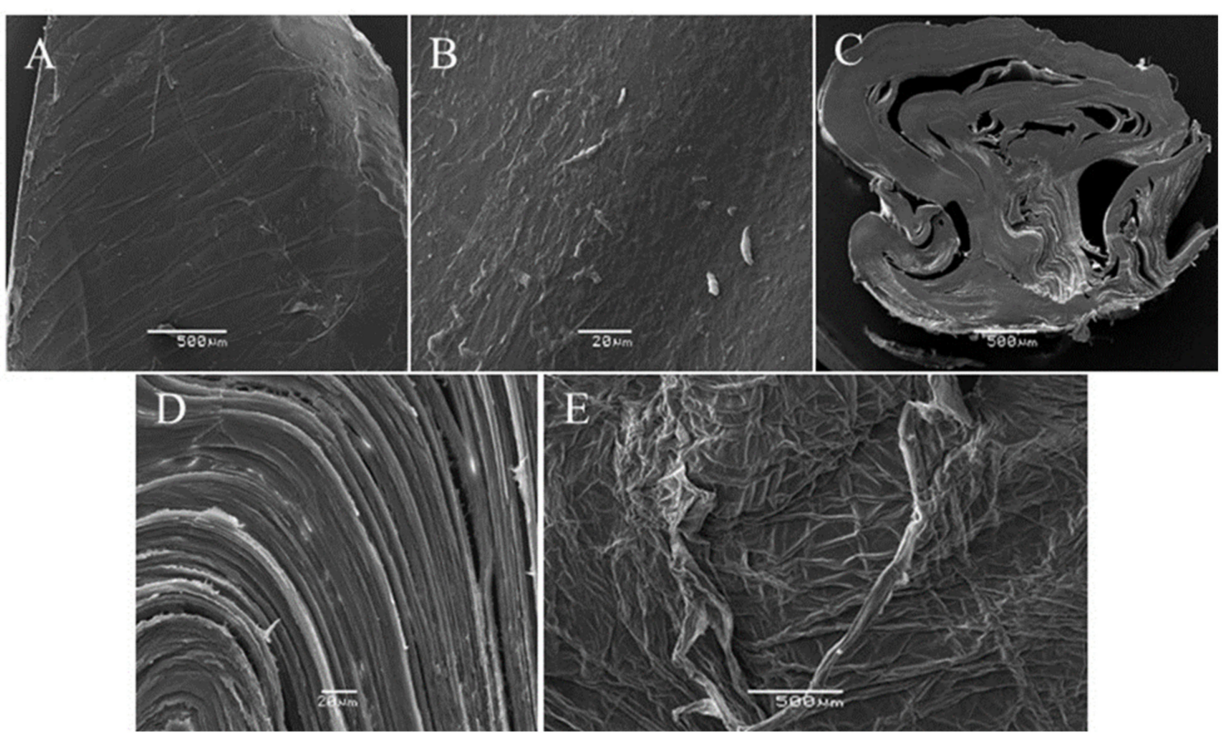

Figure 4. SEM micrograph of Dodeciduos gigas gladius blade region surface (A,B), cross-section view of gladius center $(\mathbf{C}, \mathbf{D})$, and $\beta$-chitin surface $(\mathbf{E})$.

On the other hand, the thermogram corresponding to the decomposition of $\beta$-chitin showed two-stage degradation step mechanisms. In the first stage, $3.6 \%$ of weight loss occurred due to the water evaporation, followed by a second degradation step with the maximum decomposition temperature at $325{ }^{\circ} \mathrm{C}$, which describes the polymer chain degradation. In this stage, the associated mass loss was $59.4 \%$. This is a complex process where simultaneous monomer dehydration, chain scission, and thermal decomposition of glucosamine and $\mathrm{N}$-acetylated units occurs [4]. Consequently, chain packing is loosened. Hence, a relatively small amount of heat is required for its degradation [32]. This result agrees with those found during thermal degradation of $\beta$-chitin isolated from Loligo vulgaris gladii [33]. Finally, the results are summarized in Table 2.

Table 2. Thermal analysis results from squid pen and $\beta$-chitin decomposition process.

\begin{tabular}{ccccc}
\hline \multirow{2}{*}{ Sample } & \multicolumn{3}{c}{ Temperature $\left({ }^{\circ} \mathbf{C}\right)$} & \multirow{2}{*}{ Weight Loss (\%) } \\
\cline { 2 - 4 } & $\mathbf{T}_{\text {Onset }}$ & $\mathbf{T}_{\max }$ & $\mathbf{T}_{\text {End }}$ & \\
\hline \multirow{3}{*}{ Squid pen } & 25 & 46 & 126 & 23.0 \\
& 127 & 223 & 264 & 22.8 \\
\multirow{3}{*}{ 3-Chitin } & 264 & 294 & 550 & 20.2 \\
& 25 & 86 & 193 & 3.6 \\
& 193 & 325 & 550 & 59.4 \\
\hline
\end{tabular}

\subsubsection{SEM Analysis}

The surface structure of squid pen and isolated $\beta$-chitin were studied, and their morphology is presented in Figure 4. The SEM micrographs showed that the squid gladius blade region had a rough and fibrous surface morphology (Figure 4A,B). The micrographs from the cross-section view of the same material (Figure 4C,D) showed that the squid gladius blade was composed of large microfiber (5-10 $\mu \mathrm{m}$ diameter) aggregates. Similar fibrous morphology was observed in the gladius from other squid species [33]. It is known that proteins and $\beta$-chitin chemically form squid gladius [34]. Moreover, the squid gladius's hierarchical structure was reproduced at the nanoscale and it was found that $\beta$-chitin nanocrystallites were wrapped in a protein layer to form nanofibrils. These were the building blocks of $200 \mathrm{~nm}$ sized nanofibers. The nanofibers aggregated into $2 \mu \mathrm{m}, 10 \mu \mathrm{m}, 100 \mu \mathrm{m}$, and $500 \mu \mathrm{m}$ thick fibers, respectively, which eventually formed the gladius. 
In the case of $\beta$-chitin surface analysis (Figure $4 \mathrm{E}$ ), a highly fibrous structure was observed. This could be associated with the preparation methodology, which allowed for the removal of the protein that surrounded the chitin fibers by a smooth alkaline treatment. Such morphology has been associated with the chain arrangement in $\beta$-chitin crystals that are packed in a parallel manner. In this polymorphic structure, the carbonyl oxygen of the $-\mathrm{NHCOCH}_{3}$ group is involved in intermolecular hydrogen bonding between the primary $-\mathrm{OH}$ and $-\mathrm{NH}$ groups, forming a two-dimensional hydrogen bond network in a plane perpendicular to the chitin pyranosyl plane [35].

\subsection{Nanofibrillated $\beta$-Chitin Characterization \\ 2.3.1. Viscosity}

As a result of the fibrillation process, the macromolecular fiber entanglement is separated into individual fibers. Then, a conversion from a low-viscosity chitin suspension to a high-viscosity gel network formation occurs. Viscosimetry is a cheap and widespread technique used to measure the polysaccharides solution viscosity at an industrial scale. Hence, it can be used to follow the progress of chitin defibrillation in acidic aqueous media. Results from viscosity measurements of nanofibrillated chitin gels obtained after different cycle numbers (pass through collision machine) are presented in Figure 5. It can be observed that the $1 \mathrm{wt} \%$ chitin suspension viscosity increased along with the cycle number from 10 to 60 . A white gel with good stability at low temperatures $\left(4^{\circ} \mathrm{C}\right)$ can be obtained this way. It is known that a high aspect ratio (length/diameter) or longer and thinner chitin nanofibers promotes the entanglement possibility within nanofibrils, improving the shear viscosity of the suspension.

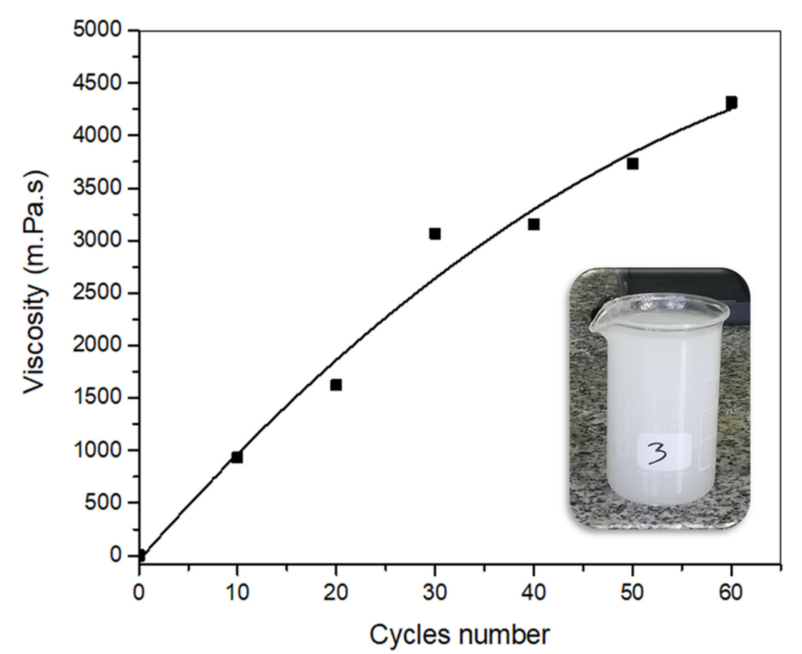

Figure 5. Viscosity of NFCh gels ( $\mathrm{pH} 3$ ) obtained after different cycle numbers (collision time) and picture of gel obtained after 60 cycles.

\subsubsection{TEM Analysis}

TEM analysis was performed to study the effect of the fibrillation process on the $\beta$ chitin hierarchical structure. For this purpose, dilutions of the fibrillated gels obtained after different fibrillation cycles were studied. Results are presented in Figure 6. All samples were analyzed at a gel concentration of $0.01 \mathrm{wt} \%$ due to the high concentration of originally obtained nanofibers. It can be observed that after 20 cycles (collision time), there was still the presence of microfibrils in the suspension gel. The width (diameter) of $\beta$-chitin nanofiber was in the range of 100-250 nm and it did not disperse uniformly. Thicker fibers in the range of $600 \mathrm{~nm}$ could also be detected. 

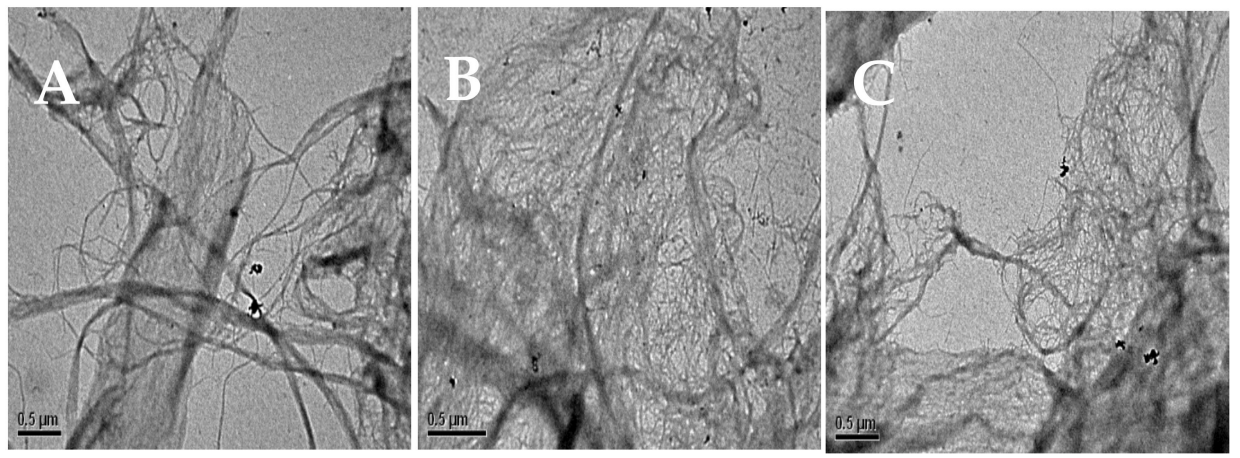

Figure 6. TEM micrograph of nanofibrillated $\beta$-chitin after different fibrillation cycles: (A) 20 cycles, (B) 40 cycles, and (C) 60 cycles.

Conversely, from 40 cycles onward, the processing of nanofibers was improved, and the decrease in nanofiber diameter within an increase of cycles through collision equipment from 40 to 60 was noted. The obtained $\beta$-chitin nanofibers after 60 cycles had a mean diameter in the range of $10-15 \mathrm{~nm}$. A similar nanofibril diameter $(6.4-6.9 \mathrm{~nm})$ was previously observed for $\beta$-chitin nanofiber prepared from Loligo vulgaris at different $\mathrm{pH}$ levels [36] and from Todarodes pacificus (5-10 $\mathrm{nm}$ ) [5].

\subsection{Nanofibrous $\beta$-Chitin Film Preparation and Characterization}

One of the main drawbacks of chitin application is their very low solubility in common organic solvents and their solubility in complex solvent mixtures. It makes processing difficult to obtain novel materials with industrial applications such as films, sponges, nano/microparticles, fibers, aerogels, and composite materials. Recently, ionic liquids and other alkali-based solvents have been proposed to overcome this issue [37-40]. However, in all cases, there is still a need for solvent removal. Nanofibrillated chitin gels obtained in an acidic aqueous solution ( $\mathrm{pH} 3$ ) offer a unique possibility to process chitin-based materials in different forms and shapes for different applications. For instance, it can be used as reinforced material for biocomposite preparation [41] and it can be readily processed into films, hydrogels, or aerogels $[8,16,42]$. In the present work, the preparation and characterization of nanofibrillated chitin films are presented (Figure 7). This is only one example of their feasibility to be handled. This process takes advantage of chitin nanofibrils natural tendency to self-assemble in aqueous media to form $\beta$-chitin fibers [36].

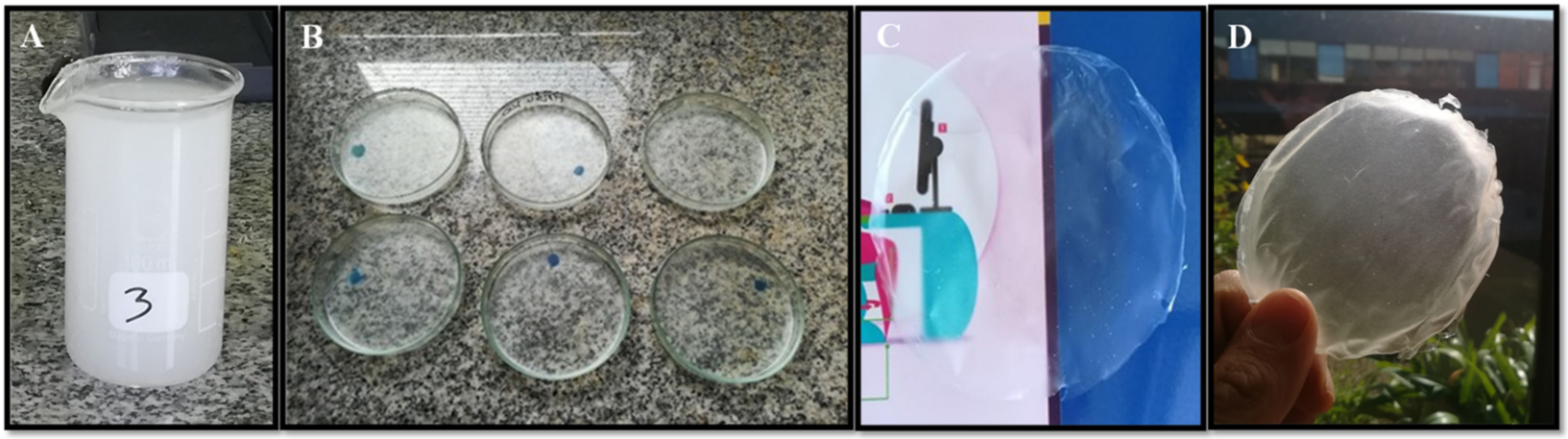

Figure 7. Camera photography of the process preparation of NF $\beta$-chitin films by the solvent casting method. Chitin nanofibrillated gel (1 wt \%) (A), casting films with different amount of gels $1 \mathrm{wt} \%(15,20,30 \mathrm{~mL}$ from left to right) (B), and resulting films with different thickness: $0.03 \mathrm{~mm}(\mathbf{C})$ and $0.05 \mathrm{~mm}(\mathbf{D})$. 


\subsubsection{X-ray Diffraction (XRD) Analysis}

The crystalline structure of the $\beta$-chitin, nanofibrillated $\beta$-chitin film, and nanofibrillated $\beta$-chitin foam was analyzed by $\mathrm{x}$-ray diffraction. The corresponding diffractograms are shown in Figure 8.

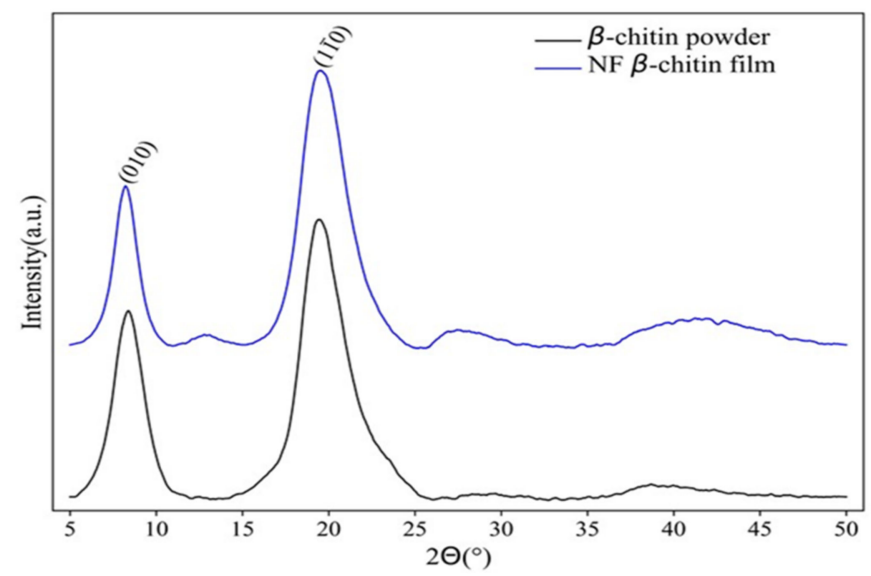

Figure 8. X-ray diffraction (XRD) diffractogram of $\beta$-chitin microfibril powder (black line) and film samples (blue line).

It is important to underline that $\beta$-chitin nanofibrils in films showed a similar pattern as $\beta$-chitin microfibril powder (see Table 3 ). This means that the $\beta$-chitin crystal structure is preserved after mechanical treatment. The diffractogram of $\beta$-chitin powder displays two broad peaks at $2 \theta=8.22^{\circ}$ (inter-sheet distance: $10.76 \AA$ ) and $2 \theta=19.32^{\circ}(4.59 \AA$ ), which corresponds to the crystal plane [010] and [11̄0] reflection values, respectively [7,32]. The crystallinity index of $\beta$-chitin microfibril powder was $69.7 \%$, which indicates a high crystalline structure. This value was higher than that obtained for chitin from squid pen L. vulgaris (58\%) [30], similar to the one found for squid pen of the same specie $(67 \%)$ caught in the Northern Hemisphere [43], and slightly lower than for chitin obtained from squid pen Illex argentinus (75\%) [11]. The crystallinity index of the $\beta$-chitin nanofibrils film is slightly lower than that for the $\beta$-chitin microfibril powder. Moreover, the peak of the [110] plane of NF $\beta$-chitin shifted to a higher value, indicating a decrease in $d$-spacing (see Table 3). The $d$ spacing values found for the $\beta$-chitin powder agreed with those previously reported (10.0 and 4.5) for this specie [43]. The $D_{a p}$ values in the perpendicular direction of the [010] plane were 6.0 , and $4.7 \mathrm{~nm}$ for the original squid pen $\beta$-chitin and the nanofibers, respectively. This is an indication that the crystallite size in the [010] plane region decreases during fibrillation. These values are higher than those found in similar products obtained from the squid pen of T. pacificus (4 and $3.5 \mathrm{~nm}$ ) [44]. According to these authors, the specific surface areas highly increased during the fibrillation process, and disordered regions in the XRD analysis were explained by the contact of nanofibers with the water. This could explain the lower crystallinity and crystallite size reduction in the NF $\beta$-chitin samples. All of these results confirm the disintegration of $\beta$-chitin powder into nanofibrous $\beta$-chitin during the mechanical treatment.

Table 3. X-ray diffraction (XRD) analysis of $\beta$-chitin samples.

\begin{tabular}{|c|c|c|c|c|c|}
\hline \multirow{2}{*}{ Sample } & \multicolumn{2}{|c|}{$d$-Spacing ( $(\AA)$} & \multicolumn{2}{|c|}{$\mathrm{D}_{\mathrm{ap}}(\mathrm{nm})$} & \multirow{2}{*}{ CI (\%) } \\
\hline & (010) & $(1 \overline{1} 0)$ & (010) & $(1 \overline{1} 0)$ & \\
\hline$\beta$-chitin powder & 10.76 & 4.59 & 6.00 & 2.60 & 69.7 \\
\hline NF $\beta$-chitin film & 10.05 & 4.48 & 4.70 & 2.60 & 68.0 \\
\hline
\end{tabular}




\subsubsection{SEM Analysis of Films}

In order to study the morphology of the obtained chitin nanofiber films, SEM analysis was performed. The results are presented in Figure 9. The surface of the nanofibrillated chitin film had a non-continuous rough and fibrous morphology (Figure 9A). At higher magnification (Figure 9B), a fiber collapse shape with some porosities could be seen. The side view (cross-section) depicts the films' inner fibrous appearance (Figure 9C,D) and shows a formed three-dimensional interconnected network under the surface. It is important to note that chitin films seem to be self-assembled in nanofiber sheets. These micrographs confirm the high defibrillation reached during chitin processing at the bench scale.

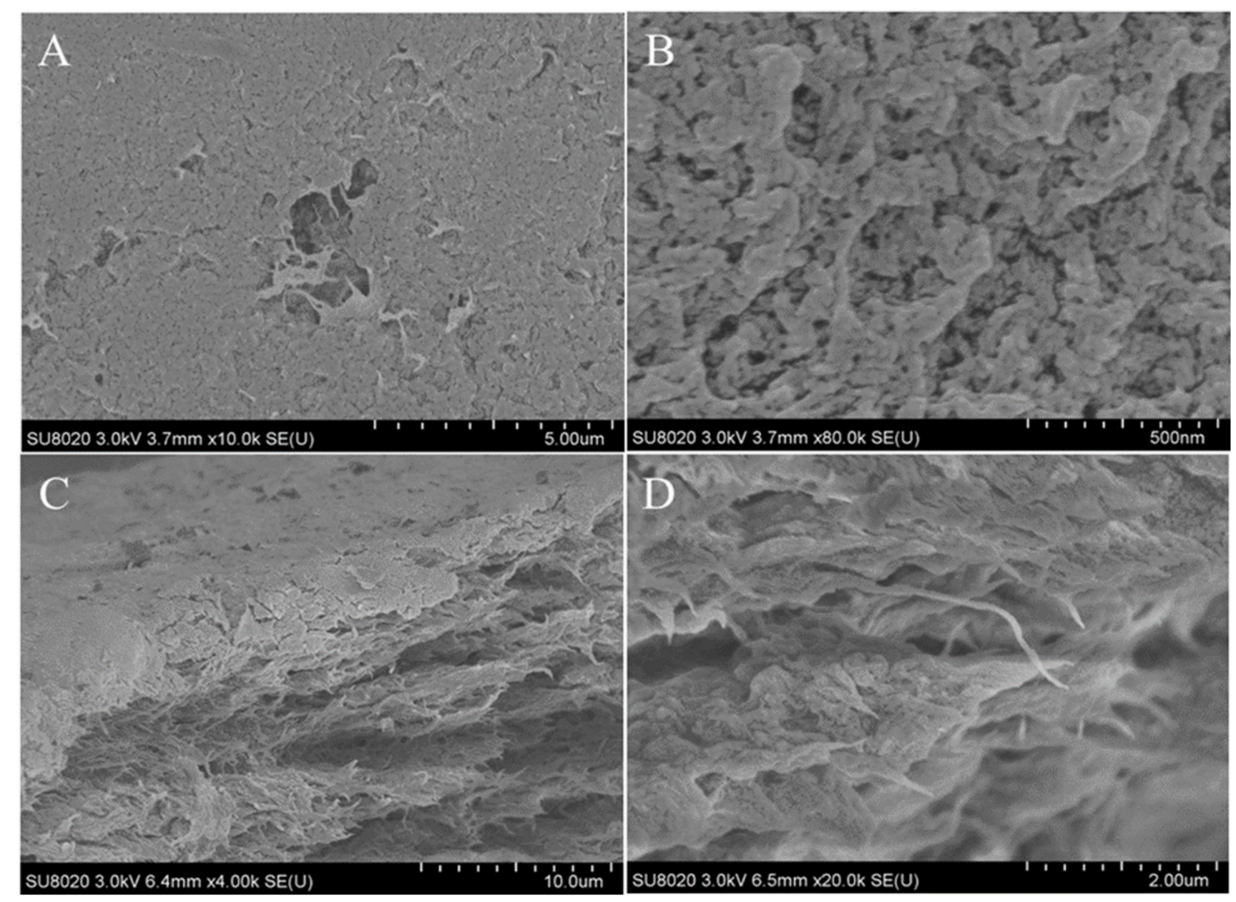

Figure 9. SEM micrographs of cryo-fractured NF $\beta$-chitin film's surface $(\mathbf{A}, \mathbf{B})$ and the crosssection $(\mathbf{C}, \mathbf{D})$.

\subsubsection{Mechanical, Colorimetric, and Swelling Degree Properties}

Mechanical properties of the $\beta$-chitin nanofiber films with different thicknesses were evaluated and are presented in Table 4. As the thickness of film increased from 0.02 to $0.05 \mathrm{~mm}$, the tensile strength of the film increased significantly (from 3.9 to $17.4 \mathrm{MPa}$ ), whereas elongation at break decreased (from 3.5 to $1.7 \%$ ). The Young's modulus of $\beta$ chitin films also increased from 0.9 to $1.1 \mathrm{GPa}$. The mechanical parameters obtained in this work were in the same range as the data from the literature for other chitin films. Namely, Kaya et al. showed that $\mathrm{E}$ and TS values of $\alpha$-chitin films extracted from $B$. giganteus cockroach dorsal pronotum (thickness $0.07 \mathrm{~mm}$ ) were $492 \mathrm{MPa}$ and $11.7 \mathrm{MPa}$, respectively, and the elongation at break was $3.3 \%$. These parameters for chitin films extracted from cockroach wings (thickness $0.01 \mathrm{~mm}$ ) were $476 \mathrm{MPa}, 6.2 \mathrm{MPa}$, and $2.2 \%$, respectively [45]. Other authors reported that nanofibrillated $\alpha$-chitin films (thickness $0.06 \mathrm{~mm}$ ) from crab showed E and TS values of $3.3 \mathrm{GPa}$ and $32 \mathrm{MPa}$, respectively. However, they found a lower e value (1.3\%) [46]. Furthermore, Ifuku et al. informed that NF $\alpha$ chitin films (thickness $0.06 \mathrm{~mm}$ ) had a Young's modulus of $2.5 \mathrm{GPa}$ and a TS of $44 \mathrm{MPa}$, respectively [47]. It is worth noting that those films had higher thicknesses than those from this work, affecting the final mechanical properties. Other authors have studied $\beta$-chitin nanofiber preparation from squid pen, and they found that the resulting film's (thickness $0.045 \mathrm{~mm})$ mechanical properties $(\mathrm{E}=2.8 \mathrm{GPa}, \mathrm{TS}=19 \mathrm{MPa})$ changed with the number of passes during preparation [48]. The $\beta$-loss in chitin nanofiber crystallinity accounted 
for the decrease in TS observed from 10 to 50 passes, while the E values remained almost constant. In these previous works, the fiber cross-sectional width was near half (3-9 nm) that obtained in the present work, and it is known that thinner and larger nanofibers show higher mechanical properties. In general, the mechanical properties of NF films are influenced by chitin chemical composition (e.g., Mw, CI, DA) and nanofiber structure (length/width ratio), which in turn depends on the biopolymer source along with the isolation procedure, and the NF preparation methods $[43,49,50]$. Other properties that could affect the nanofibrillated chitin film mechanical properties are the porosity, protein content, thickness, preparation method, and NF orientation [51-53]. Finally, these NF were prepared at a laboratory scale under controlled conditions. Considering this fact, the obtained results from this work at a bench-scale are auspicious if this cheaper process would be further scaled.

Table 4. Mechanical, swelling degree, and colorimetric parameters of $\beta$-chitin nanofiber films.

\begin{tabular}{|c|c|c|c|c|c|c|c|c|c|c|}
\hline \multirow{2}{*}{$\begin{array}{l}\text { Thickness } \\
\text { (mm) }\end{array}$} & \multirow{2}{*}{ E (GPa) } & \multirow{2}{*}{ TS (MPa) } & \multirow{2}{*}{ e $(\%)$} & \multicolumn{3}{|c|}{ Swelling Degree (\%) } & \multicolumn{4}{|c|}{ CIELAB } \\
\hline & & & & pH 4 & pH 6 & pH 8 & $\mathbf{L}^{*}$ & $a^{*}$ & $\mathbf{b}^{*}$ & $\Delta \mathrm{E}^{*}$ \\
\hline 0.02 & 0.9 & 3.94 & 3.46 & $294 \pm 12$ & $291 \pm 15$ & $257 \pm 16$ & 91.88 & -0.273 & 1.647 & 3.43 \\
\hline 0.05 & 1.1 & 17.4 & 1.74 & $287 \pm 14$ & $283 \pm 12$ & $263 \pm 13$ & 91.34 & -0.226 & 1.712 & 3.87 \\
\hline
\end{tabular}

In order to check the colorimetric parameters of the obtained chitin nanofiber films and their changes within the different thickness of films, the CIELAB color system test was applied. According to the parameters presented in Table 4, the films had a high $\mathrm{L}^{*}$ value, which means that they had high lightness. The negative $a^{*}$ value and positive $b^{*}$ value indicated that films were green-yellowish. $\Delta \mathrm{E}^{*}$ is a parameter that can show the difference in the color between the samples. In this paper, the color differences among chitin nanofiber films of different thicknesses were tested toward the blank white surface. As can be seen, the $\Delta \mathrm{E}^{*}$ value was not significantly different for two different chitin nanofiber films, which means that there was no significant difference in their color. Moreover, the values of $\Delta \mathrm{E}^{*}$ were above 3 , indicating that color change is visually perceivable.

The swelling degree of $\beta$-chitin nanofiber films was measured at three different $\mathrm{pH}$ values $(4,6$, and 8$)$. As shown in Table 4 , the swelling degree of the tested films slightly decreased when the $\mathrm{pH}$ increased from $\mathrm{pH} 4$ to $\mathrm{pH}$ 6. However, these changes were not significant. In addition, there were no significant changes in the swelling degree value between films of different thicknesses. On the other hand, under alkaline conditions, all swelling degree of all tested films decreased in a range of $7-12 \%$. This result is expected since it is known that the $\mathrm{pK} 0$ of chitosan is around 6-6.5. At $\mathrm{pH} 4$, there are positively charged glucosamine units in chitin chains, and hydrogen bonding with the molecules of water occurs. However, due to the high DA of $\beta$-chitin, the low amount of free-glucosamine units in the backbone are not enough to provoke a significant change in the degree of swelling of those films. As the $\mathrm{pH}$ increases and switches to the alkaline environment, the amine groups from chitin become deprotonated, which leads to repulsion interaction between the chitin chain and water molecules and reduced the swelling degree.

Finally, the biodegradable chitin nanofibers obtained in the current process could find application in several areas. For instance, it can be used as reinforced materials to obtain nanocomposites with improved mechanical and higher barrier properties against humidity and gases $\left(\mathrm{O}_{2}\right.$ and $\left.\mathrm{CO}_{2}\right)$ [54]. This flexible and transparent nanomaterial can be used in food packaging applications to replace petroleum-based polymers. Moreover, chitin NF is using for food Pickering emulsion stabilization. This is due to its polycationic nature, capable of interacting with anionic proteins to stabilize the emulsion drops by hydrogen bond and hydrophobic interaction [55].

Additionally, chitin nanofibers can be used to prepare novel biological adhesives [56]. In the biomedical field, several biomaterials (e.g., films, membranes, aerogels) containing chitin nanofibers have been prepared. These were tested as a wound dressing and con- 
trolled release devices [57,58]. Furthermore, due to the antimicrobial properties of chitin nanofibers, they can be used in agriculture to protect plants against plant diseases and promote plant growth $[59,60]$. It is expected that the number of chitin NF applications will increase shortly, and some of them will reach the market, thus in this way triggering the commercial production of this material at a low cost.

\section{Materials and Methods}

\subsection{Materials}

Giant Humbold squid (Dosidicus gigas) was caught on the Chilean coast during the 2018-2019 season. Squid pen was provided by Landes Fishery Company (Concepción City, Chile) in a wet form. All reagents, $\mathrm{HCl}, \mathrm{NaOH}, \mathrm{KBr}, 2,6-$ bis(1,1-dimethylethyl)4-methylphenol (BHT), methanol, chloroform, $\mathrm{LiCl}$, and $\mathrm{N}, \mathrm{N}$-dimethylacetamide were purchased from Merk (Chile)

\section{2. $\beta$-Chitin Isolation at Bench Scale}

First, squid pens (gladius) were washed with tap water to separate the remaining protein debris. The samples were cut in pieces using a cutting mill SM 200 (Retsch GmbH, Germany) to obtain samples of particles size ranging from $1-3 \mathrm{~cm}$. Pen sample $(7 \mathrm{~kg}) \mathrm{was}$ demineralized with $1 \mathrm{M}$ hydrochloric acid (solids to solvent ratio of 1:10 w/v) at room temperature for $2 \mathrm{~h}$ in a steel reactor. The mixture was mechanically stirred at $600 \mathrm{rpm}$. The demineralized sample was filtered and washed with deionized water until the washing became neutral ( $\mathrm{pH}$ 7) and dried at $60{ }^{\circ} \mathrm{C}$ for $24 \mathrm{~h}$. The deproteinization procedure was carried out in the same reactor, where the solid was stirred with $1 \mathrm{M}$ sodium hydroxide (solids to solvent ratio of $1: 20 \mathrm{w} / \mathrm{v}$ ) at $100{ }^{\circ} \mathrm{C}$ for $3 \mathrm{~h}$. The isolated $\beta$-chitin was washed with distilled water and dried at $60{ }^{\circ} \mathrm{C}$ in a vacuum oven and then weighted to determine yield percent.

\subsection{Characterization of Squid Pen and Isolated $\beta$-Chitin}

\subsubsection{Water and Ash Content}

Squid pen water content was determined gravimetrically. Each sample was placed in a porcelain crucible and heated at $105^{\circ} \mathrm{C}$ in a Thermo oven (Thermo Fischer Scientific, Waltham, MA, USA) up to the constant weight. Later, the dried sample was placed in a muffle Thermo (Thermo Fischer Scientific, Waltham, MA, USA) and heated at $900{ }^{\circ} \mathrm{C}$ in order to determine the ash content [1]. Each procedure was performed in triplicate. The same methodology was followed for chitin samples.

\subsubsection{Total Protein Content}

The total protein content (TPC) was measured by elemental analysis and calculated according to the following equation:

$$
\mathrm{TPC}(\%)=(N(\%)-6.9) \times 6.25
$$

where $N \%$ represents the percentage of nitrogen determined by elemental analysis for each sample; 6.9 corresponds to the theoretical percentage of nitrogen in fully acetylated chitin (this value was adjusted as a function of the degree of acetylation); and 6.25 corresponds to the theoretical percentage of nitrogen in proteins. All the determinations were done in triplicate.

\subsubsection{Chitin Content}

The chitin content was estimated by the method reported by Black and Schwartz [2]. Namely, $0.5 \mathrm{~g}$ of sample was immersed in $50 \mathrm{~mL}$ of $0.1 \mathrm{M} \mathrm{HCl}$, and the flask was heated at $100{ }^{\circ} \mathrm{C}$ for $1 \mathrm{~h}$. Afterward, the flask was cooled to room temperature, and the content was centrifuged at $3500 \times g \mathrm{rpm}$ for $10 \mathrm{~min}$. The supernatant was separated from the precipitate, mixed with $45 \mathrm{~mL}$ of fresh DI water, and the resultant suspension was centrifuged again. This step was continuously repeated until the washing was no longer acidic. Then, $50 \mathrm{~mL}$ 
of $1.25 \mathrm{M} \mathrm{NaOH}$ solution was added to the chitin pulp product, and the mixture was heated at $100{ }^{\circ} \mathrm{C}$ for $1 \mathrm{~h}$. At the end of this period, the mixture was centrifuged at $3500 \times \mathrm{g} \mathrm{rpm}$ for $10 \mathrm{~min}$. The supernatant was carefully decanted from the precipitate, and $45 \mathrm{~mL}$ of fresh DI water was added, and the resultant suspension centrifuged. This process was repeated until the washings were no longer basic. Finally, the precipitate was washed twice with $50 \mathrm{~mL}$ acetone. The resulting precipitate was placed into a crucible and dried in the oven at $110{ }^{\circ} \mathrm{C}$ to constant weight. The residue should consist of chitin and silica present in the sample. The contents of the crucible were incinerated to constant weight in an electric muffle-furnace at a dull red heat $\left(770{ }^{\circ} \mathrm{C}\right)$ until all carbonaceous matter was consumed. The crucible was cooled down and reweighed. The loss in weight was reported as chitin and compared to the original mass of the sample to examine the content of chitin.

\subsubsection{Total Lipid Content}

Total lipid content was determined according to the established method [61], but with slight modification [62]. Squid pen (10 g) was blended in a top-drive blender for 2 min with a mixture of distilled water $(4 \mathrm{~mL})$, methanol $(20 \mathrm{~mL})$, and chloroform $(10 \mathrm{~mL})$. An additional amount of chloroform $(10 \mathrm{~mL})$ was added, and the mixture was mixed in a vortex for $30 \mathrm{~s}$. Distilled water $(10 \mathrm{~mL})$ was added to the mixture and vortexed for $30 \mathrm{~s}$. The mixture was filtered under pressure on a glass filter. The content was collected in a separating funnel and the two layers were isolated. The water-methanol layer was removed by suction and the chloroform layer was recovered and concentrated on a rotary evaporator. The solute was finally dried in a Thermo vacuum oven (Thermo Fischer Scientific, Waltham, MA, USA). During the process, a few crystals of 2,6-bis(1,1-dimethylethyl)-4-methylphenol $(\mathrm{BHT})$ were added to the samples to prevent oxidation. All the lipid extracts were weighed, and the lipid content percentage was calculated.

\subsubsection{Infrared Spectroscopy Analysis}

Fourier transform infrared (FTIR) spectra were recorded by a Nicolet Magna FTIR spectrophotometer (Nicolet Analytical Instruments, Madison, WI, USA). The spectrophotometer is connected to a PC with OMNIC ${ }^{\text {TM }}$ software (Thermo Electron Corp., Woburn, MA, USA) to process data. The samples were prepared in $\mathrm{KBr}$ pellets at a concentration of $2 \%(w / w)$. The transmission spectra were recorded at $4 \mathrm{~cm}^{-1}$ resolution and 64 scans.

\subsubsection{Thermogravimetric Analysis}

The thermogravimetric studies were performed by a thermogravimetric analyzer Cahn-Ventron 2000 (Cahn Scientific, Irvine, CA, USA) with a microprocessor driven temperature control unit and a thermal analysis data station. The weight of the samples ranged between 5 and $10 \mathrm{mg}$. The aluminum sample pan was placed in the balance system equipment, and the temperature was raised from 25 to $550{ }^{\circ} \mathrm{C}$ at a heating rate of $10^{\circ} \mathrm{C} \mathrm{min}-1$

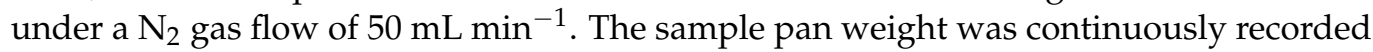
as a function of temperature.

\subsubsection{Solid-State Cross-Polarization/Magic Angle Spinning ${ }^{13} \mathrm{C}$ NMR Spectroscopy (CP/MAS ${ }^{13} \mathrm{C}$ NMR)}

The solid-state $\mathrm{CP} / \mathrm{MAS}{ }^{13} \mathrm{C}-\mathrm{NMR}$ spectra of chitin samples were registered in a Bruker AMX 300 spectrometer (Bruker, Billerica, MA, USA). In all cases, 3072 scans were accumulated. The contact time was $1 \mathrm{~ms}$, the repetition time $5 \mathrm{~s}$, and the acquisition time was $50 \mathrm{~ms}$. The internal reference ( 0 ppm) was 4,4-dimethyl-4-silapentane-1-sulfonic acid (DSS). The chitin degree of acetylation (DA\%) was determined from the spectrum using the ratio between the intensities $(I)$ of the $-\mathrm{CH}_{3}$ group signal and the sum of the intensities of all carbon signals from the glucopyranosic ring, according to the following equation:

$$
\mathrm{DA}(\%)=\left(\frac{I_{C H 3}}{I_{C 1}+I_{C 2}+I_{C 3}+I_{C 4}+I_{C 5}+I_{C 6} / 6}\right) \times 100
$$




\subsubsection{Scanning Electron Microscopy (SEM)}

Morphological analysis was performed on an ETEC autoscan Model U-1 scanning electron microscope (University of Massachusetts, Worcester, MA, USA). The samples were fixed in a sample holder and covered with a gold layer for 3 min, using an Edwards S150 sputter coater (BOC Edwards, São Paulo, Brazil).

\subsubsection{Reduced Viscosity Determination}

The reduced viscosity of $\beta$-chitin was determined by an Ubbelohde capillary viscometer in a water bath at $25 \pm 0.1^{\circ} \mathrm{C}$. First, $\beta$-chitin was dissolved in $\mathrm{N}, \mathrm{N}$-dimethylacetamide/ $\mathrm{LiCl}$ $5 \mathrm{wt} \%$, at a polymer concentration of $0.03 \mathrm{~g} \mathrm{~d} . \mathrm{L}^{-1}$ at $25^{\circ} \mathrm{C}$. The relative $\left(\eta_{r}\right)$, specific $\left(\eta_{s p}\right)$, and reduced viscosities $\left(\eta_{\text {red }}\right)$ of solutions were calculated according to the following equations:

$$
\begin{gathered}
\eta_{r}=\frac{\eta}{\eta_{0}} \\
\eta_{s p}=\eta_{r}-1 \\
\eta_{r e d}=\frac{\eta_{s p}}{c}=\frac{\left(\eta_{r}-1\right)}{c}
\end{gathered}
$$

where $\eta$ is the viscosity of the solution (or dispersion); $\eta_{0}$ is the viscosity of the solvent; and $c$ is the (mass) concentration in $\mathrm{g} \cdot \mathrm{mL}^{-1}$. The reduced viscosity is expressed in $\mathrm{mL} \cdot \mathrm{g}^{-1}$.

\subsubsection{0. $\beta$-Chitin Nanofibrils (NF) Preparation at Bench Scale}

The $\beta$-chitin powder $(2.1 \mathrm{~kg}$ ) was ground in a blade mil IKA (IKA WERKLE, Staufen, Germany) and sieved up to a particle size $2 \mathrm{~mm}$ in diameter. The obtained solid ( $2 \mathrm{~kg})$ was suspended in distilled water $(200 \mathrm{~L})$ at $1 \mathrm{wt} \%$. The $\mathrm{pH}$ of the slurry was set up with $\mathrm{HCl}$ to $\mathrm{pH} 3$, and the slurry was disintegrated using a proprietary massive collider operated at $25^{\circ} \mathrm{C}$ (Figure 10). The $\beta$-chitin slurries were made to shear the fibers apart by passing the fibers through a 12-inch rotating disc. The disk gap was first set to zero, corresponding to the starting point, where the two disks graze without pulp. The mechanical defibrillation machine was operated at $1 \mathrm{~atm}$ pressure. The equipment loaded with a $1 \mathrm{wt} \%$ chitin suspension (viscosity close to cero) was fibrillated at $1200 \mathrm{rpm}$. The disintegrated $\beta$-chitin was sampled at different cycles and finally recovered. The number of collision times (=cycle pass) was set to $10,20,40$, and 60 passes. The obtained nanofibrous material was in the form of a concentrated suspension with a gel-like appearance. Figure 10 shows the NF $\beta$-chitin processing at a bench scale.

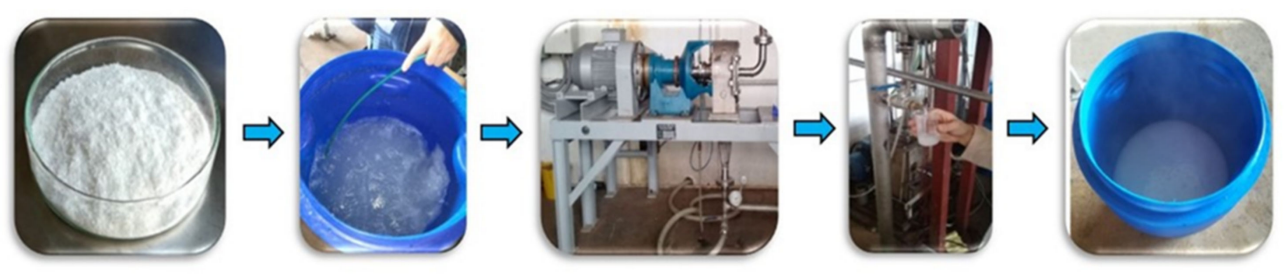

Figure 10. Processing of NF $\beta$-chitin at bench scale using a massive collider machine.

\subsection{Physicochemical Characterization of $\beta$-Chitin Nanofibrils}

\subsubsection{Viscosimetry}

The viscosity of the nanofibrillated gels was measured in a rotational viscometer (Fungilab, Barcelona, Spain) at $25^{\circ} \mathrm{C}$ using a TL7 spin for all samples.

\subsubsection{Transmission Electron Microscopy (TEM)}

The chitin nanofibrillated samples were diluted to obtain a $0.01 \mathrm{wt} \%$ solution. The solution drops were placed in a $\mathrm{Cu}$ grid of 100 mesh and dried at room temperature. Then, the samples were analyzed by JEOL JEM 1200 EX II TEM equipment (JEOL, Tokyo, Japan). 


\subsubsection{X-ray Diffraction (XRD)}

XRD diffractograms of chitin samples were obtained in order to evaluate their crystallite size and crystalline index. This analysis provided information about the changes in the crystalline structure of differently processed chitin nanofibrils. The XRD analysis was performed by a Bruker AXS model D4 Endeavor diffractometer (Bruker AXS GmgH, Karlsruhe, Germany) using monochromatic $\mathrm{CuK} \alpha$ radiation $(\lambda=0.15418)$. The device generated a signal at $40 \mathrm{kV}$ and $20 \mathrm{~mA}$. The intensities were measured in the range of $5^{\circ}<2 \theta<40{ }^{\circ} \mathrm{C}$ for all samples, with a step size of $0.02^{\circ}$ and scans at one s/step. The intersheet distance was determined by Equation (6). The apparent crystallite size (Dap) was calculated using the Scherrer equation (Equation (7)), while the crystalline index (CrI) was calculated using Equation (8):

$$
n \times \lambda=2 \times d \times \sin \theta
$$

where $n$ is the order of reflection; $\lambda$ is the radiation wavelength (in nm); and $\theta$ is the plane angle.

$$
\text { Dap }=\frac{K \times \lambda}{\beta \cos \theta}
$$

where $\beta$ (in radians) was the half-width of the reflection; $K$ was a constant, indicating the crystallite perfection, equal to $0.9 ; \lambda$ was the radiation wavelength (in $\mathrm{nm}$ ); and $\theta$ was the plane angle.

$$
\mathrm{CrI}=\frac{A_{\text {Cryst }} \times 100}{A_{\text {Total }}}
$$

where $A_{\text {Cryst }}$ was the sum of all crystalline signals and $A_{\text {Total }}$ was the total area of the diffractogram.

\subsection{Preparation of Nanofibrous $\beta$-Chitin Films}

In order to obtain the nanofibrillated films of different thicknesses $(0.02$ and $0.05 \mathrm{~mm})$, different volumes of concentrated nanofibrous chitin suspension ( $1 \mathrm{wt} \%$ ) were placed in Petri dishes and dried in a Thermo vacuum oven (Thermo Fischer Scientific, Waltham, MA, USA) at $60^{\circ} \mathrm{C}$ for $24 \mathrm{~h}$.

\subsection{Characterization of Films}

The obtained nanofibrous $\beta$-chitin films were subjected to XRD and SEM analysis, as described in Sections 3.3.8 and 3.4.3, respectively.

Mechanical, Colorimetric, and Swelling Degree Analysis

Mechanical analysis was performed on a universal testing machine SmarTens 005 (KARG Industrietechnik, Krailling, Germany), with a load cell of $1 \mathrm{kN}$ and at $23 \pm 2{ }^{\circ} \mathrm{C}$, $45 \pm 5 \% \mathrm{RH}$. The tensile test was performed on nanofibrous $\beta$-chitin film with a width of $5 \mathrm{~mm}$ and length of $3 \mathrm{~cm}$. The crosshead speed was $2 \mathrm{~mm} / \mathrm{min}$. All mechanical analyses were carried out in triplicate.

In order to evaluate the color changes of the $\beta$-chitin nanofiber films of different thicknesses, colorimetric analysis was performed by a Biobase BCM-200 colorimeter (Biobase Meihua Co, Jinan, China). Two measurements (center and border) were taken on each sample. Colorimetric parameters were obtained using the CIELAB color scale to measure color: $L^{*}=0$ (black) to $L^{*}=100$ (white); $-a^{*}$ (greenness) to $+a^{*}$ (redness); and $-b^{*}$ (blueness) to $+b^{*}$ (yellowness). A white $\left(L_{0}^{*}=94.3 ; a_{0}^{*}=-0.9 ; b_{0}{ }^{*}=-0.7\right)$ standard color was used for equipment calibration. The color difference $(\Delta E)$ was calculated according to the following equation:

$$
\Delta E^{*}=\sqrt{\left(L_{0}^{*}-L^{*}\right)^{2}+\left(a_{0}^{*}-a^{*}\right)^{2}+\left(b_{0}^{*}-b^{*}\right)^{2}}
$$


In order to check the swelling degree of chitin, the film samples were cut into $1 \times 1 \mathrm{~cm}^{2}$ slices, and then the samples were kept in a desiccator with silica-gel for seven days. After this procedure, the samples were weighed and then subjected to immersion in glass vessels containing $10 \mathrm{~mL}$ of different buffer solutions ( $\mathrm{pH} 4, \mathrm{pH} 6$, and $\mathrm{pH} 8$ ). After $24 \mathrm{~h}$, samples were removed, put on tissue paper, weighed, and analyzed/recorded by a camera. The swelling degree (SD\%) was calculated by Equation (10):

$$
\mathrm{SD}(\%)=\frac{m_{t}-m_{0}}{m_{0}} * 100
$$

where $m_{0}$ and $m_{t}$ are the initial weight and weight in a specific time interval.

\section{Conclusions}

This work presented the efficient extraction of $\beta$-chitin from marine-waste, squid pens of Dosidicus gigas. The $\beta$-form of chitin was confirmed by FTIR and NMR analysis. The degree of acetylation was $96 \%$, as evaluated by NMR. Successful conversion of $\beta$-chitin into nanofibers at a semi-industrial scale was carried out in a collider machine under acidic conditions, which XRD, SEM, and TEM confirmed. It was shown that the number of passes of chitin through the collider machine could significantly influence the nanometer scale of the fibers. Namely, after 10 passes through the collider machine, the obtained $\beta$-chitin was in the form of visible microfibrils and nanofibrils. On the other hand, above 20 passes, the conversion of $\beta$-chitin to nanofibers was significantly improved, and the obtained nanofibers were in the range between 10 and $15 \mathrm{~nm}$. The obtained nanofibers after the collider machine were in the gel-like form and were further converted into films by the solvent-casting method. Due to moderate swelling degree and good mechanical resistance, these $\beta$-chitin nanofibrous films have the potential to be further developed into food packaging, agricultural, wound dressing, or 3D-bioink material. Hence, the present work demonstrated a promising approach of utilization and industrial conversion of marine waste to $\beta$-chitin functional material with versatile potentials.

Author Contributions: C.G., K.P.M., O.G., J.C., O.V., G.B.: methodology, software, formal analysis, investigation, validation; C.D. and H.Y.: visualization, supervision, investigation; G.C.-B., O.V.: project administration, investigation, writing — original draft preparation, writing - review and editing; A.N.: investigation, funding acquisition, writing-original draft preparation, writingreview and editing. All authors have read and agreed to the published version of the manuscript.

Funding: This research was funded by Agencia Nacional de Investigación y Desarrollo (ANID, Chile) through projects FONDECYT REGULAR 1210107, CONICYT PIA/APOYO CCTE AFB170007, REDES 190181, and FONDECYT REGULAR 1191528.

Data Availability Statement: The data presented in this study are available inside the manuscript.

Conflicts of Interest: The authors declare no conflict of interest.

\section{References}

1. Vázquez, J.A.; Sotelo, C.G.; Sanz, N.; Pérez-Martín, R.I.; Rodríguez-Amado, I.; Valcarcel, J. Valorization of Aquaculture ByProducts of Salmonids to Produce Enzymatic Hydrolysates: Process Optimization, Chemical Characterization and Evaluation of Bioactives. Mar. Drugs 2019, 17, 676. [CrossRef]

2. Al Khawli, F.; Pateiro, M.; Domínguez, R.; Lorenzo, J.M.; Gullón, P.; Kousoulaki, K.; Ferrer, E.; Berrada, H.; Barba, F.J. Innovative Green Technologies of Intensification for Valorization of Seafood and Their By-Products. Mar. Drugs 2019, 17, 689. [CrossRef] [PubMed]

3. Giannetto, A.; Esposito, E.; Lanza, M.; Oliva, S.; Riolo, K.; Di Pietro, S.; Abbate, J.M.; Briguglio, G.; Cassata, G.; Cicero, L.; et al. Protein Hydrolysates from Anchovy (Engraulis encrasicolus) Waste: In Vitro and In Vivo Biological Activities. Mar. Drugs 2020, 18, 86. [CrossRef] [PubMed]

4. Bernabé, P.; Becherán, L.; Cabrera-Barjas, G.; Nesic, A.; Alburquenque, C.; Tapia, C.V.; Taboada, E.; Alderete, J.; De Los Ríos, P. Chilean crab (Aegla cholchol) as a new source of chitin and chitosan with antifungal properties against Candida spp. Int. J. Biol. Macromol. 2020, 149, 962-975. [CrossRef]

5. Bastiaens, L.; Soetemans, L.; D'Hondt, E.; Elst, K. Sources of Chitin and Chitosan and Their Isolation. In Chitin and Chitosan: Properties and Applications; van den Broek, L.A.M., Boeriu, C.G., Eds.; John Wiley \& Sons: Hoboken, NJ, USA, 2019 ; pp. 1-34. 
6. Hamed, I.; Özogul, F.; Regenstein, J.M. Industrial Applications of Crustacean By-Products (Chitin, Chitosan, and Chitooligosaccharides): A Review. Trends Food Sci. Technol. 2016, 48, 40-50. [CrossRef]

7. Suenaga, S.; Nikaido, N.; Totani, K.; Kawasaki, K.; Ito, Y.; Yamashita, K.; Osada, M. Effect of purification method of $\beta$-chitin from squid pen on the properties of $\beta$-chitin nanofibers. Int. J. Biol. Macromol. 2016, 91, 987-993. [CrossRef]

8. Ma, Q.; Pang, K.; Wang, K.; Huang, S.; Ding, B.; Duan, Y.; Zhang, J. Ultrafine and carboxylated $\beta$-chitin nanofibers prepared from squid pen and its transparent hydrogels. Carbohydr. Polym. 2019, 211, 118-123. [CrossRef] [PubMed]

9. Uranga, J.; Etxabide, A.; Cabezudo, S.; de la Caba, K.; Guerrero, P. Valorization of marine-derived biowaste to develop chitin/fish gelatin products as bioactive carriers and moisture scavengers. Sci. Total Environ. 2020, 706, 135747. [CrossRef] [PubMed]

10. Saito, T.; Kuramae, R.; Wohlert, J.; Berglund, L.A.; Isogai, A. An Ultrastrong Nanofibrillar Biomaterial: The Strength of Single Cellulose Nanofibrils Revealed via Sonication-Induced Fragmentation. Biomacromolecules 2013, 14, 248-253. [CrossRef]

11. Susana Cortizo, M.; Berghoff, C.F.; Alessandrini, J.L. Characterization of chitin from Illex argentinus squid pen. Carbohydr. Polym. 2008, 74, 10-15. [CrossRef]

12. Cuong, H.N.; Minh, N.C.; Van Hoa, N.; Trung, T.S. Preparation and characterization of high purity $\beta$-chitin from squid pens (Loligo chenisis). Int. J. Biol. Macromol. 2016, 93, 442-447. [CrossRef] [PubMed]

13. Lavall, R.; Assis, O.; Campana-Filho, S. $\beta$-Chitin from the pens of Loligo sp.: Extraction and characterization. Bioresour. Technol. 2007, 98, 2465-2472. [CrossRef]

14. Suenaga, S.; Totani, K.; Nomura, Y.; Yamashita, K.; Shimada, I.; Fukunaga, H.; Takahashi, N.; Osada, M. Effect of acidity on the physicochemical properties of $\alpha$ - and $\beta$-chitin nanofibers. Int. J. Biol. Macromol. 2017, 102, 358-366. [CrossRef] [PubMed]

15. Ifuku, S.; Yamada, K.; Morimoto, M.; Saimoto, H. Nanofibrillation of Dry Chitin Powder by Star Burst System. J. Nanomater. 2012, 2012, 645624. [CrossRef]

16. Lu, Y.; Sun, Q.; She, X.; Xia, Y.; Liu, Y.; Li, J.; Yang, D. Fabrication and characterisation of $\alpha$-chitin nanofibers and highly transparent chitin films by pulsed ultrasonication. Carbohydr. Polym. 2013, 98, 1497-1504. [CrossRef] [PubMed]

17. Ifuku, S.; Nogi, M.; Abe, K.; Yoshioka, M.; Morimoto, M.; Saimoto, H.; Yano, H. Preparation of chitin nanofibers with a uniform width as $\alpha$-chitin from crab shells. Biomacromolecules 2009, 10, 1584-1588. [CrossRef] [PubMed]

18. Salaberria, A.M.; Fernandes, S.C.M.; Diaz, R.H.; Labidi, J. Processing of $\alpha$-chitin nanofibers by dynamic high pressure homogenization: Characterization and antifungal activity against A. niger. Carbohydr. Polym. 2015, 116, 286-291. [CrossRef] [PubMed]

19. Morganti, P. Chitin-Nanofibrils in skin treatment. J. Appl. Cosmetol. 2009, 27, 251-270.

20. Danti, S.; Trombi, L.; Fusco, A.; Azimi, B.; Lazzeri, A.; Morganti, P.; Coltelli, M.-B.; Donnarumma, G. Chitin Nanofibrils and Nanolignin as Functional Agents in Skin Regeneration. Int. J. Mol. Sci. 2019, 20, 2669. [CrossRef]

21. Zhu, Y.; Huan, S.; Bai, L.; Ketola, A.; Shi, X.; Zhang, X.; Ketoja, J.A.; Rojas, O.J. High Internal Phase Oil-in-Water Pickering Emulsions Stabilized by Chitin Nanofibrils: 3D Structuring and Solid Foam. ACS Appl. Mater. Interfaces 2020, 12, 11240-11251. [CrossRef]

22. Coltelli, M.-B.; Gigante, V.; Panariello, L.; Aliotta, L.; Morganti, P.; Danti, S.; Cinelli, P.; Lazzeri, A. Chitin Nanofibrils in Renewable Materials for Packaging and Personal Care Applications. Adv. Mater. Lett. 2019, 10, 425-430.

23. Seggiani, M.; Cinelli, P.; Verstichel, S.; Puccini, M.; Vitolo, S.; Anguillesi, I.; Lazzeri, A. Development of Fibres-Reinforced Biodegradable Composites. Chem. Eng. Trans. 2015, 43, 1813-1815.

24. Youn, D.K.; No, H.K.; Prinyawiwatkul, W. Preparation and characteristics of squid pen $\beta$-chitin prepared under optimal deproteinisation and demineralisation condition. Int. J. Food Sci. Technol. 2013, 48, 571-577. [CrossRef]

25. Abdelmalek, B.E.; Sila, A.; Haddar, A.; Bougatef, A.; Ayadi, M.A. $\beta$-Chitin and chitosan from squid gladius: Biological activities of chitosan and its application as clarifying agent for apple juice. Int. J. Biol. Macromol. 2017, 104, 953-962. [CrossRef]

26. Subhapradha, N.; Ramasamy, P.; Sudharsan, S.; Seedevi, P.; Moovendhan, M.; Srinivasan, A.; Shanmugam, V.; Shanmugam, A. Preparation of phosphorylated chitosan from gladius of the squid Sepioteuthis lessoniana (Lesson, 1830) and its in vitro antioxidant activity. Bioact. Carbohydr. Diet. Fibre 2013, 1, 148-155. [CrossRef]

27. Tolaimate, A.; Desbrieres, J.; Rhazi, M.; Alagui, A. Contribution to the preparation of chitins and chitosans with controlled physico-chemical properties. Polymer 2003, 44, 7939-7952. [CrossRef]

28. Cárdenas, G.; Cabrera, G.; Taboada, E.; Miranda, S.P. Chitin characterization by SEM, FTIR, XRD, and 13 C cross polarization/mass angle spinning NMR. J. Appl. Polym. Sci. 2004, 93, 1876-1885. [CrossRef]

29. Chaussard, G.; Domard, A. New Aspects of the Extraction of Chitin from Squid Pens. Biomacromolecules 2004, 5, 559-564. [CrossRef] [PubMed]

30. Methacanon, P.; Prasitsilp, M.; Pothsree, T.; Pattaraarchachai, J. Heterogeneous N-deacetylation of squid chitin in alkaline solution. Carbohydr. Polym. 2003, 52, 119-123. [CrossRef]

31. Perez, J.J.; Villanueva, M.E.; Sánchez, L.; Ollier, R.; Alvarez, V.; Copello, G.J. Low cost and regenerable composites based on chitin/bentonite for the adsorption potential emerging pollutants. Appl. Clay Sci. 2020, 194, 105703. [CrossRef]

32. Balitaan, J.N.I.; Yeh, J.-M.; Santiago, K.S. Marine waste to a functional biomaterial: Green facile synthesis of modified- $\beta$-chitin from Uroteuthis duvauceli pens (gladius). Int. J. Biol. Macromol. 2020, 154, 1565-1575. [CrossRef] [PubMed]

33. Ianiro, A.; Giosia, M.; Fermani, S.; Samorì, C.; Barbalinardo, M.; Valle, F.; Pellegrini, G.; Biscarini, F.; Zerbetto, F.; Calvaresi, M.; et al. Customizing Properties of $\beta$-Chitin in Squid Pen (Gladius) by Chemical Treatments. Mar. Drugs 2014, 12, 5979-5992. [CrossRef]

34. Yang, F.-C.; Peters, R.D.; Dies, H.; Rheinstädter, M.C. Hierarchical, self-similar structure in native squid pen. Soft Matter 2014, 10, 5541-5549. [CrossRef] 
35. Nishiyama, Y.; Noishiki, Y.; Wada, M. X-ray Structure of Anhydrous $\beta$-Chitin at $1 \AA$ Resolution. Macromolecules 2011, 44, 950-957. [CrossRef]

36. Montroni, D.; Marzec, B.; Valle, F.; Nudelman, F.; Falini, G. $\beta$-Chitin Nanofibril Self-Assembly in Aqueous Environments. Biomacromolecules 2019, 20, 2421-2429. [CrossRef]

37. Silva, S.S.; Gomes, J.M.; Rodrigues, L.C.; Reis, R.L. Marine-Derived Polymers in Ionic Liquids: Architectures Development and Biomedical Applications. Mar. Drugs 2020, 18, 346. [CrossRef] [PubMed]

38. Fang, Y.; Zhang, R.; Duan, B.; Liu, M.; Lu, A.; Zhang, L. Recyclable Universal Solvents for Chitin to Chitosan with Various Degrees of Acetylation and Construction of Robust Hydrogels. ACS Sustain. Chem. Eng. 2017, 5, 2725-2733. [CrossRef]

39. Roy, J.C.; Salaün, F.; Giraud, S.; Ferri, A.; Chen, G.; Guan, J. Solubility of Chitin: Solvents, Solution Behaviors and Their Related Mechanisms. In Solubility of Polysaccharides; InTech: London, UK, 2017.

40. Shamshina, J.L.; Berton, P. Use of Ionic Liquids in Chitin Biorefinery: A Systematic Review. Front. Bioeng. Biotechnol. 2020, 8 , 1-14. [CrossRef]

41. Joseph, B.; Mavelil Sam, R.; Balakrishnan, P.; Maria, H.J.; Gopi, S.; Volova, T.; Fernandes, S.C.M.; Thomas, S. Extraction of Nanochitin from Marine Resources and Fabrication of Polymer Nanocomposites: Recent Advances. Polymers 2020, $12,1664$.

42. Suenaga, S.; Osada, M. Preparation of $\beta$-Chitin Nanofiber Aerogels by Lyophilization. Int. J. Biol. Macromol. 2019, 126, 1145-1149. [CrossRef]

43. Jung, J.; Zhao, Y. Alkali- or acid-induced changes in structure, moisture absorption ability and deacetylating reaction of $\beta$-chitin extracted from jumbo squid (Dosidicus gigas) pens. Food Chem. 2014, 152, 355-362. [CrossRef] [PubMed]

44. Fan, Y.; Saito, T.; Isogai, A. Preparation of Chitin Nanofibers from Squid Pen $\beta$-Chitin by Simple Mechanical Treatment under Acid Conditions. Biomacromolecules 2008, 9, 1919-1923. [CrossRef] [PubMed]

45. Kaya, M.; Sargin, I.; Sabeckis, I.; Noreikaite, D.; Erdonmez, D.; Salaberria, A.M.; Labidi, J.; Baublys, V.; Tubelytė, V. Biological, mechanical, optical and physicochemical properties of natural chitin films obtained from the dorsal pronotum and the wing of cockroach. Carbohydr. Polym. 2017, 163, 162-169. [CrossRef]

46. Mushi, N.E. A Review on Native Well-Preserved Chitin Nanofibrils for Materials of High Mechanical Performance. Int. J. Biol. Macromol. 2021, 178, 591-606. [CrossRef]

47. Ifuku, S. Chitin and Chitosan Nanofibers: Preparation and Chemical Modifications. Molecules 2014, 19, 18367-18380. [CrossRef] [PubMed]

48. Dutta, A.K.; Izawa, H.; Morimoto, M.; Saimoto, H.; Ifuku, S. Simple Preparation of Chitin Nanofibers from Dry Squid Pen $\beta$-Chitin Powder by Star Burst System. J. Chitin Chitosan Sci. 2013, 1, 186-191. [CrossRef]

49. Mushi, N.E.; Nishino, T.; Berglund, L.A.; Zhou, Q. Strong and Tough Chitin Film from $\alpha$-Chitin Nanofibers Prepared by High Pressure Homogenization and Chitosan Addition. ACS Sustain. Chem. Eng. 2019, 7, 1692-1697. [CrossRef]

50. Wu, Q.; Jungstedt, E.; Šoltésová, M.; Mushi, N.E.; Berglund, L.A. High Strength Nanostructured Films Based on Well-Preserved $\beta$-Chitin Nanofibrils. Nanoscale 2019, 11, 11001-11011. [CrossRef]

51. Zhang, X.; Rolandi, M. Engineering Strategies for Chitin Nanofibers. J. Mater. Chem. B 2017, 5, 2547-2559. [CrossRef]

52. Fazli Wan Nawawi, W.M.; Lee, K.Y.; Kontturi, E.; Murphy, R.J.; Bismarck, A. Chitin Nanopaper from Mushroom Extract: Natural Composite of Nanofibers and Glucan from a Single Biobased Source. ACS Sustain. Chem. Eng. 2019, 7, 6492-6496. [CrossRef]

53. Ezekiel Mushi, N.; Butchosa, N.; Zhou, Q.; Berglund, L.A. Nanopaper Membranes from Chitin-Protein Composite NanofibersStructure and Mechanical Properties. J. Appl. Polym. Sci. 2014, 131, 1-9. [CrossRef]

54. Wu, J.; Zhang, K.; Girouard, N.; Meredith, J.C. Facile Route to Produce Chitin Nanofibers as Precursors for Flexible and Transparent Gas Barrier Materials. Biomacromolecules 2014, 15, 4614-4620. [CrossRef]

55. Kaku, Y.; Fujisawa, S.; Saito, T.; Isogai, A. Synthesis of Chitin Nanofiber-Coated Polymer Microparticles via Pickering Emulsion. Biomacromolecules 2020, 21, 1886-1891. [CrossRef] [PubMed]

56. Azuma, K.; Nishihara, M.; Shimizu, H.; Itoh, Y.; Takashima, O.; Osaki, T.; Itoh, N.; Imagawa, T.; Murahata, Y.; Tsuka, T.; et al. Biological Adhesive Based on Carboxymethyl Chitin Derivatives and Chitin Nanofibers. Biomaterials 2015, $42,20-29$. [CrossRef] [PubMed]

57. Jayakumar, R.; Prabaharan, M.; Nair, S.V.; Tamura, H. Novel Chitin and Chitosan Nanofibers in Biomedical Applications. Biotechnol. Adv. 2010, 28, 142-150. [CrossRef]

58. Fuyuan, D.; Hongbing, D.; Yumin, D.; Xiaowen, S.; Qun, W. Emerging Chitin and Chitosan Nanofibrous Materials for Biomedical Application. Nanoscale 2014, 6, 9477-9493.

59. Aklog, Y.F.; Egusa, M.; Kaminaka, H.; Izawa, H.; Morimoto, M.; Saimoto, H.; Ifuku, S. Protein/CaCo3/Chitin Nanofiber Complex Prepared from Crab Shells by Simple Mechanical Treatment and Its Effect on Plant Growth. Int. J. Mol. Sci. 2016, 17, 1600. [CrossRef]

60. Egusa, M.; Matsui, H.; Urakami, T.; Okuda, S.; Ifuku, S.; Nakagami, H.; Kaminaka, H. Chitin Nanofiber Elucidates the Elicitor Activity of Polymeric Chitin in Plants. Front. Plant Sci. 2015, 6, 1-7. [CrossRef]

61. Bligh, E.G.; Dyer, W.J. A rapid method of total lipid extraction and purification. Can. J. Biochem. Physiol. 1959, 37, 911-917. [CrossRef]

62. Hardy, R.; Keay, J.N. Seasonal variations in the chemical composition of Cornish mackerel, Scomber scombrus (L), with detailed reference to the lipids. Int. J. Food Sci. Technol. 2007, 7, 125-137. [CrossRef] 